Original Article

\title{
FORMULATION OPTIMIZATION, CHARACTERIZATION AND IN VITRO ANTI-CANCER ACTIVITY OF CURCUMIN LOADED NANOSTRUCTURED LIPID CARRIERS
}

\author{
JINAL SHAH ${ }^{1}$, SHOAIB PATEL ${ }^{2}$, SRINIVAS BHAIRY ${ }^{3}$, RAJASHREE HIRLEKAR ${ }^{4}$ \\ 1,2,3,4Department of Pharmaceutics, Vivekanand Education Society's College of Pharmacy (Affiliated to University of Mumbai), Hashu \\ Advani Memorial Complex, Behind Collector Colony, Chembur (E), Mumbai 400074, Maharashtra, India \\ Email: rajashree.hirlekar@ves.ac.in
}

Received: 10 Sep 2021, Revised and Accepted: 15 Nov 2021

\begin{abstract}
Objective: The present study was aimed at preparing stable lyophilized curcumin loaded nanostructured lipid carriers (NLCs). The optimized lyophilized curcumin loaded NLCs were characterized and evaluated for various quality control parameters.

Methods: The optimized curcumin loaded NLCs were prepared by modified hot emulsification using precirol ATO 5 (PRE), capmul MCM C8 EP (CAP) as solid and liquid lipids, respectively. The combination of tween 80 (T80) and solutol HS 15 (SHS) were used as an emulsifier. The NLCs dispersion was lyophilized into powder form to improve the thermodynamic stability of the formulation. The lyophilized curcumin loaded NLCs were evaluated for particle size, size distribution, zeta potential, entrapment efficiency (EE), drug loading, assay, in vitro drug release, crystallinity and surface morphology studies.

Results: The optimized lyophilized curcumin loaded NLCs have a mean particle size of $286.2 \pm 11.5 \mathrm{~nm}$ with a size distribution of $0.288 \pm 0.011$, a zeta potential of $0.247 \pm 0.025 \mathrm{mV}$ with high entrapment of $98.20 \pm 1.53 \%$ and drug loading of $2.50 \pm 0.21 \%$. The X-ray diffraction and endothermic peaks confirmed the maximum encapsulation of curcumin in lipid matrices. The particles were spherical with smooth surface morphology. In vitro release studies showed sustained release for up to $24 \mathrm{~h}$. The cytotoxicity against human lung cancer line A-549 for curcumin-loaded NLCs was confirmed with positive control adriamycin (ADR).
\end{abstract}

Conclusion: Curcumin-loaded NLCs prepared had a nanosize particle distribution with maximum entrapment efficiency. Dispersion stability was increased by the lyophilisation process. The solid lyophilized powder is reconstituted for oral delivery.

Keywords: Curcumin, Nanostructured lipid carrier, Lyophilization, Anti-cancer activity

(C) 2022 The Authors. Published by Innovare Academic Sciences Pvt Ltd. This is an open access article under the CC BY license (https://creativecommons.org/licenses/by/4.0/)

DOI: https://dx.doi.org/10.22159/ijcpr.2022v14i1.44110 Journal homepage: https://innovareacademics.in/journals/index.php/ijcpr

\section{INTRODUCTION}

A polyphenolic compound, curcumin, targets various signalling compounds at the cellular level [1]. As Curcumin is a natural product, it is of great interest, safe, inexpensive and easily accessible for cancer therapy. Curcumin potently effects intracellularly by altering important processes like modulation of the genome, cell invasion and death. This shows curcumin as a promising candidate for cytostatic and cytotoxic activity. Curcumin shows its anticancer activity via inhibition of transcription factors and downstream gene products, antiproliferative action, affecting growth factor receptors, altering cell adhesion molecules in angiogenesis, negative regulation of inflammatory cytokines, and protein kinases altering the growth of tumours and metastasis. Recently published literature showed antitumor activity, possibly by inhibition of telomerase $[2,3]$. The uptake of curcumin in cancer cells is higher than in normal cells because of lower levels of glutathione in cancer cells, which increases their sensitivity to curcumin [4]. The interaction of curcumin on normal rat hepatocytes showed no superoxide generation and further no cell death. Hence, curcumin has no cytotoxic effect on normal cells $[5,6]$. Oral administration of $2 \mathrm{~g}$ of pure curcumin showed a plasma concentration of less than $10 \mathrm{ng} / \mathrm{ml}$ at $1 \mathrm{~h}$ postdose in healthy human volunteers [7]. Low plasma levels of curcumin are due to poor solubility and high first-pass metabolism and intestinal metabolism including glucuronidation and sulfation on oral administration [8]. The major degradation products of curcumin are ferulic acid and vanillin, which also show biological activity, including cytotoxicity [9]. Due to the poor aqueous solubility and bioavailability of curcumin, the use of lipophilic substances in lipid-based nanosystems can improve the solubility and bioavailability of curcumin. Previously, curcumin loaded NLCs were evaluated for enhanced solubility $[10,11]$, bioavailability [12], anti-inflammatory [13], topical administration
$[14,15]$, chronic wound healing [16], antibacterial [17], neuroprotective potential in Alzheimer's disease [18], ocular delivery [19], targeted delivery to mitochondria [20], brain [21]. The cytotoxic activity of curcumin loaded NLCs were previously reported against human HepG2 cells [22], astrocytoma-glioblastoma cell line (U373MG) [23], Caco-2 cell [24], brain cancer [25, 26], HeLa cells [27], human lung adenocarcinoma A549 cells [28]. In the present study, we evaluated in vitro cytotoxic activity against cell lines of non-small cell lung cancer for optimized curcumin NLC formulation.

\section{MATERIALS AND METHODS}

\section{Materials}

Curcumin of purity $99.50 \%$ was obtained from VAV Life Science (Mumbai, India) as a gift sample. Precirol ATO 5 (PRE), Geleole (GLE), Labrafac lipophile WL 1349 (LAF), Capryol PGMC (CPR) were gift samples obtained from Gattefosse, India. Dynasan 114 (D114), Dynasan 116 (D116), Dynasan 118 (D118), Miglyol 812 (MIG) were gift samples obtained from Cremer Oleo $\mathrm{GmbH}$ and Co. Germany. Capmul MCM C8 EP (CAP) was a gift sample obtained from Indchem International, India. Tween 80 (T80), Polaxomer 188 (P188), Solutol HS 15 (SHS), Kolliphore EL (KEL), Kolliphore RH 40 (KRH40) were gift samples obtained from BASF, India. Olive oil, sesame oil, sunflower oil and rice bran oil were purchased from Kamani oil Industries, India. Stearic acid and Palmitic acid were purchased from Lobachemie, India. Lactose monohydrate (SuperTab 11SD) was a gift sample obtained from DFE Pharma, India. Mannitol (Pearlitol 200SD) and Dextrose (dextrose monohydrate GC) were obtained from Roquette, India. as a gift sample. Directly compressible sucrose (Compressuc PS) was obtained from Tereos, France as a gift sample. The methanol used was of high-performance liquid chromatography (HPLC) grade and obtained from LOBA-Chemie. Millipore (ultrapure) water was used for the preparation of all solutions. 


\section{Formulation development of lyophilized curcumin loaded NLCs}

\section{Screening of excipients}

The solubility of curcumin was performed for screening of suitable formulation excipients by a semi-quantitative method. The solid lipids were melted $5{ }^{\circ} \mathrm{C}$ higher than their melting point and curcumin was added to the molten mass, then mixed in a vortex mixer (Remi CM 101 Plus; Remi Labs, India) for uniform mixing and determining the maximum amount of curcumin that could be dissolved in each lipid. These solutions were checked for the presence or absence of curcumin visually and the process was continued till the lipid got saturated with the curcumin. The lipid with the highest solubility for curcumin was chosen for further studies [14]. A similar procedure was used for screening of liquid lipid, emulsifier and the ratio of solid lipid to liquid lipid (heating was applied for only solid components) [29].

\section{Method of preparation}

In modified hot melt emulsification, the emulsifiers, solid lipid and liquid lipids are placed in a test tube. This preconcentrate is warmed at a temperature of $5{ }^{\circ} \mathrm{C}$ above the melting point of the solid lipid. Curcumin is dissolved in this preconcentrate. On the other hand, a beaker containing water is placed on a preheated magnetic stirrer (Remi Ltd., India) at the same temperature. Then the preconcentrate is added to the water maintained at the same temperature under stirring. This mixture is kept on the magnetic stirrer (Remi Ltd., India) until a uniform emulsion is obtained [30]. Further particle size reduction was carried out using a probe sonicator (Oscar Ultrasonics Pvt Ltd., India) with a $3 \mathrm{~mm}$ horn with a 30-40 \% variac and 90-watt power (fig. 1).

\section{Preliminary screening of formulation and process-related parameters}

The formulation-related parameters like solid lipid, emulsifier and its concentration, and process-related parameters like sonication time were taken into consideration $[30,31]$. After every parameter screening, the best value of the parameter was finalized and kept as constant for the next parameter screening as mentioned in table 1 . All the formulations were prepared in triplicates.

\section{Optimization-design of experiment}

A 2-factor 2-level full factorial design $2^{2}$ was used for the optimization. The effect of various parameters on the basis of responses observed was evaluated statistically by applying one-way analysis of variance (ANOVA) using the software Design-Expert $\AA$ version 9.0.3. This helps to understand the combined effect of formulation and process-related parameters. The influence of two independent variables constituted of a formulation and a process-related parameter, emulsifier concentration (A: EC) and sonication time (B: ST) on the responses of particle size and polydispersity index (PDI) was studied. Each independent variable was varied at two levels; a high $(+1)$ and a low level (-1) as mentioned in table 2. Experimental trials were carried out in triplicates. Specific desired values for both the responses were assigned. The upper limit for particle size was specified as $220 \mathrm{~nm}$ and the upper limit for PDI was 0.200 . The EC and ST values were specified as in the range i.e. any value of EC and ST that leads to a value of the responses in the desired limit range. For each response, the response polynomial coefficients were determined in order to evaluate the effect of each factor. Each response coefficient was studied for its statistical significance by using pareto charts. The pareto charts establish the $t$ value of effect that is studied by two limit lines namely, the bonferroni limit line ( $t$ value of effect $=3.96079$ ) and the $t$ limit line ( $t$ value of effect $=2.77645$ ). Coefficients with $t$ value of effect above the bonferroni line are designated as significant coefficients; coefficients with $t$ value of effect between the bonferroni line and the $t$ limit line are termed as coefficients likely to be significant, while t value of effect below the t limit line is a statistically insignificant coefficient. Also, the contour plots and 3D design were observed for better understanding of the effect of factors on the responses observed. The desirability and overlay plot takes into consideration all the factors and their combined effect on the responses. The software suggests several solutions pertaining to the acceptance criteria specified for the factors and the responses of various solutions. An appropriate solution has to be selected as an optimized formula for the formulation.

Table 1: Preliminary screening parameters for curcumin loaded NLCs

\begin{tabular}{lll}
\hline Parameter & Preliminary screening & Variables \\
\hline Curcumin & $8 \mathrm{mg}$ & PRE, GLE, D114, D116, D118. \\
Solid lipid & $1.2 \%$ & CAP \\
Liquid lipid & $0.8 \%$ & $1 \%, 1.5 \%, 2 \%$ \\
Emulsifier & T80, SHS, T80+SHS 15 (1:1) & \\
Emulsifier concentration (EC) & $1.5 \%$ & $5,10,15 \mathrm{~min}$ \\
Purified water & $10 \mathrm{ml}$ & $10 \mathrm{~min}$ \\
Sonication time (ST) & & \\
\hline
\end{tabular}

Table 2: Factorial design for optimization of curcumin loaded NLCs

\begin{tabular}{lllll}
\hline Levels & Factors & & Response \\
\cline { 2 - 4 } & A: EC & B: $\mathbf{S T}$ & $\mathbf{1}$ & Particle Size \\
\hline High $(+1)$ & 170 & 7 & & PDI \\
Low $(-1)$ & 120 & 2 & \\
\hline
\end{tabular}

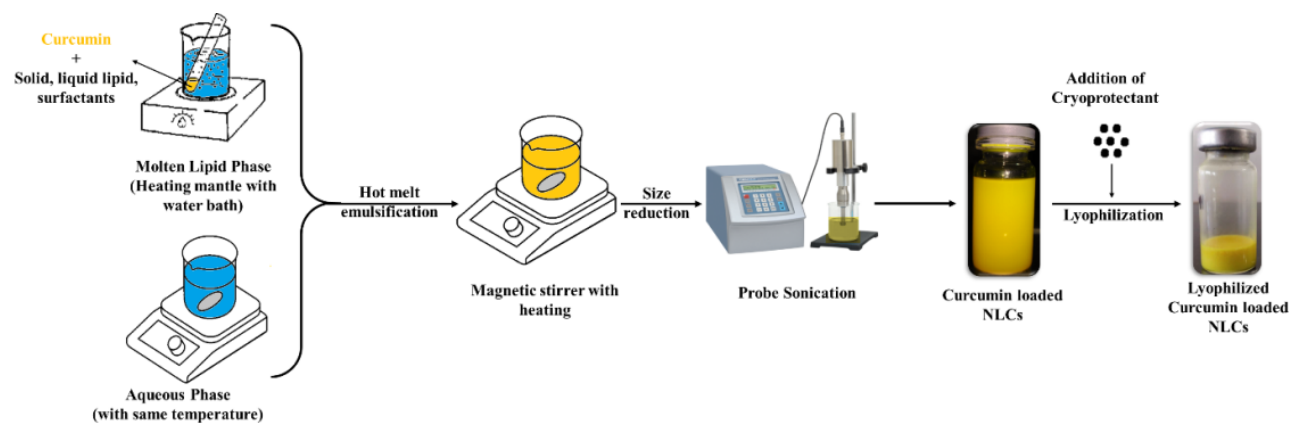

Fig. 1: Method of preparation of lyophilized curcumin loaded NLCs 


\section{Lyophilisation}

Solid dosage forms are more stable and more preferred than liquids in nanoparticle formulations. In order to improve the physical and chemical stability of liquid systems, water has to be removed. In the present study, a few cryoprotectants like lactose, sucrose, dextrose and mannitol were evaluated for lyophilisation. These cryoprotectants were screened at different concentrations. The process was carried out using freeze-thaw cycles wherein cryoprotected formulations were subjected to $12 \mathrm{~h}$ freezing, allowed to come to room temperature and to thaw for alternative cycles for a period of $3 \mathrm{~d}$. Cryoprotectants were incorporated into the formulation in specific concentrations $\mathrm{w} / \mathrm{v}$ by sufficient mixing. These formulations were filled into vials and subjected to lyophilisation. A formulation without any cryoprotectant was lyophilized to compare the effect of the cryoprotectant on particle size and PDI. An appropriate amount of curcumin NLCs formulation was dispensed into glass vials and transferred to a lyophilizer (Biocryos, Korea). Pre-freezing of the samples was done for $12 \mathrm{~h}$ at a temperature of between $-35{ }^{\circ} \mathrm{C}$ and $-40{ }^{\circ} \mathrm{C}$. Furthermore, the formulations were dried using a vacuum at a temperature of $-35{ }^{\circ} \mathrm{C}$ to $22{ }^{\circ} \mathrm{C}$. The pressure maintained during drying was 200-500 millitorr (fig. 1).

\section{Characterization and evaluation of lyophilized curcumin loaded} NLCs

\section{Redispersibility and drug content}

An equivalent amount of water was added to the lyophilized product to maintain the concentration of the drug uniformly. The ability of the lyophilized powder to reconstitute into a uniform solution was observed. For drug content, $1 \mathrm{ml}$ of curcumin-loaded NLCs were diluted with methanol in a $10 \mathrm{ml}$ volumetric flask and were sonicated in a bath sonicator (Remi Ltd., India) for $60 \mathrm{~min}$ for complete extraction of the curcumin from the nanoparticles. The solution was filtered through a nylon syringe filter of $0.45 \mu \mathrm{m}$ and further dilutions of the sample solution were made with mobile phase to obtain a final concentration of $10 \mu \mathrm{g} / \mathrm{ml}$ and this solution was injected into the HPLC system and the chromatogram was recorded as per our previously published method [32]. The percentage assay or recovery of the sample solution was then calculated by the following formula:

$$
\text { Recovery }(\%)=\frac{\text { Amount of curcumin recovered }}{\text { Amount of curcumin added }} \times 100
$$

\section{Particle size, size distribution and zeta potential}

The Malvern Zetasizer ZS90 (Malvern Instruments, UK) at a 90degree scattering angle with dynamic light scattering was used for particle size and extent of the size distribution (PDI) of curcumin NLCs. For light scattering measurements, the samples were measured at a fixed angle of $90^{\circ}$ at $25^{\circ} \mathrm{C}$. The scattering intensity was adjusted between 100-500 kcps by appropriately diluting the sample with double distilled water. The zeta potential was measured using the technique of laser doppler micro-electrophoresis by Malvern Zetasizer ZS90 (Malvern Instruments, UK). The zeta potential was measured by filling the samples into disposable zeta cell cuvettes and placing them in the sample chamber of ZS 90 .

\section{Entrapment efficiency and drug loading}

The EE of curcumin NLCs was determined by an indirect method wherein the amount of unincorporated (unentrapped) drugs in the aqueous phase of NLCs was determined. $1.5 \mathrm{ml}$ of curcumin NLCs was subjected to centrifugation using a high-speed centrifuge (Remi Ltd., India) at $14000 \mathrm{rpm}$ for $30 \mathrm{~min}$. The upper portion of the sample was separated. $0.5 \mathrm{ml}$ of this solution was further diluted with methanol and the amount of the curcumin present was analysed using an HPLC system [32].

$$
\begin{gathered}
\text { Entrapment efficiency }(\mathrm{EE})(\%)=\frac{\mathrm{Wt}-\mathrm{Wa}}{\mathrm{Wt}} \times 100 \\
\text { Drug loading }(\%)=\frac{\mathrm{Wt}-\mathrm{Wa}}{(\mathrm{Wt}-\mathrm{Wa})+\mathrm{Wl}} \times 100
\end{gathered}
$$

Where,

Wt stands for the total amount of curcumin added to the system.
Wa stands for the amount of curcumin quantified by indirect method.

Wl stands for the amount of lipid.

\section{Surface morphology}

The external surface morphology of curcumin-loaded NLCs was recorded using scanning electron microscopy (SEM) (Philips XL30 FEG, Netherlands) at $15 \mathrm{kV}$ as an accelerating voltage. A small amount of samples was mounted on an aluminium stub with double-sided adhesive tape. A thin layer of gold was sputter-coated on the stub with the sample to make the sample conductive. The sample was then subjected to analysis under different magnification levels (8000x).

\section{Crystallinity studies}

The X-ray diffractogram (XRD) measurements of lyophilized curcumin-loaded NLCs were performed on the PAN analytical X'Pert PRO MPD (Multi-Purpose Diffractometer) System. The samples were loaded onto an X-ray diffractometer and then the spectrum range of $0-5000$ intensity was observed at $2 \theta^{\circ}$. PANalytical X'Pert High Score software was used for pattern treatment, peak identification, and peak labelling. The analysis was performed for curcumin, solid lipid and curcumin-loaded NLC formulations.

\section{In vitro drug release studies}

The in vitro drug release studies from curcumin lipoidal nanoparticles were performed using the dialysis bag (molecular cutoff of 12-14 kilodalton, Sigma-Aldrich Co., India) method [11]. The adequate volume of dissolution media, constituted of $\mathrm{pH} 6.8$ phosphate buffer saline and ethanol in a ratio of $1: 1$, was maintained at $37^{\circ} \mathrm{C}$ with the agitation of $100 \mathrm{rpm}$. Aliquots volume was withdrawn and replaced with fresh buffer at predetermined time intervals. Appropriate dilutions were made and the concentration of the drug was analysed using the HPLC system [32].

The drug release data were fitted into various common release kinetics models [11] as follows:

\section{Zero-order model}

Zero-order drug release is represented by the equation: $Q_{\mathrm{t}}=Q_{0}+K_{0} t$

Where $Q_{t}$ is the amount of drug dissolved in time $t, Q_{0}$ is the initial amount of drug in the solution (most times, $\mathrm{Q} 0=0$ ), $\mathrm{K}_{0}$ is the zeroorder release constant expressed in units of concentration/time. To study the release kinetics, data obtained from in vitro drug release studies was plotted as the cumulative amount of drug released versus time.

\section{First-order model}

The release of the drug which followed first-order kinetics can be expressed by the equation: $\log C=\log \mathrm{C}_{0}-\mathrm{K}_{\square} / 2.303$

Where $\mathrm{C}_{0}$ is the initial concentration of drug, $\mathrm{k}$ is the first-order rate constant, and $t$ is the time. The data obtained is plotted as log cumulative percentage of drug remaining vs. time, which would yield a straight line with a slope of $-K / 2.303$.

\section{The higuchi model}

A mathematical model aimed at describing drug release from a matrix system was proposed by Higuchi in 1961. The model expression is given by the equation:

$$
\mathrm{Ft}=\mathrm{Q}=\mathrm{A} \sqrt{\mathrm{D}(2 \mathrm{C}-\mathrm{Cs}) \mathrm{Cst}}
$$

Where $\mathrm{Q}$ is the amount of drug released in time t per unit area $\mathrm{A}, \mathrm{C}$ is the drug's initial concentration, Cs is the drug's solubility in the matrix media, and $\mathrm{D}$ is the diffusivity of the drug molecules (diffusion coefficient) in the matrix substance. The data obtained were plotted as cumulative percentage drug release versus square root of time.

\section{Korsemeyer peppas model}

In this model, the value of $\mathrm{n}$ characterizes the release mechanism of a drug. 0.45 corresponds to a fickian diffusion mechanism, $0.45<\mathrm{n}<0.89$ corresponds to non-fickian transport, $\mathrm{n}=0.89$ to case II 
(relaxational) transport, and $n>0.89$ to super case II transport. To study the release kinetics, data obtained from in vitro drug release studies was plotted as log cumulative percentage drug release versus log time.

\section{In vitro cytotoxicity study for curcumin loaded NLCs}

In vitro cytotoxicity studies were carried out using the A-549 cell line, a representative cell line of non-small cell lung cancer. It was used to evaluate the efficiency of curcumin against lung cancer. The studies were performed to check the effectiveness of nano formulated curcumin over standard curcumin. It was also performed to check the efficacy of the nanoformulation in preventing cell growth. Analysis was carried out using three different samples. The samples consisted of curcumin-loaded NLCs formulation, curcumin dispersed in water and curcumin in dimethyl sulfoxide (DMSO). A positive control ADR was also used to confirm that the cell line was itself significant for the studies. The samples were appropriately diluted to attain concentrations of 10,20 and $40 \mu \mathrm{g} / \mathrm{ml}$. These solutions were incorporated into cultured cell lines and observed for anti-cancer activity. The LC50, GI50 and TGI values of each sample were calculated from the graph. LC50 = Concentration of drug causing $50 \%$ cell kill, GI50 = Concentration of drug causing $50 \%$ inhibition of cell growth, TGI = Concentration of drug causing total inhibition of cell growth, $\mathrm{ADR}=$ adriamycin, positive control compound.

\section{Real-time stability studies}

The optimized lyophilized curcumin loaded NLCs formulation was filled in aluminum-polyvinyl chloride (Alu-PVC) sachets and were subjected to different conditions $\left(25^{\circ} \mathrm{C} \pm 2{ }^{\circ} \mathrm{C} / 60 \% \pm 5 \% \mathrm{RH}\right.$ and $5 \pm 3$ ${ }^{\circ} \mathrm{C}$ ) as per guidelines of the international council for harmonization (ICH) for stability studies over a period of 2 mo. The formulations were evaluated for various quality control parameters.

\section{RESULTS AND DISCUSSION}

Formulation development of lyophilized curcumin loaded NLCs

\section{Screening of excipients}

The solubility of curcumin in solid lipids is in the order of PRE $>$ D116 $>$ GLE $>$ D114 $>$ D118. Palmitic and stearic acids were discontinued for further study due to their low solubility for curcumin. Curcumin solubility was higher in CAP $>$ CPR $>$ LAF $>$ MIG than in other oil components. Further, it was observed that the maximum amount of curcumin was soluble in a blend of PRE and CAP in a ratio of 60:40 when compared with various other solid lipid and liquid lipid combinations. Curcumin was degraded when added to surfactants KRH 40 and KEL. P188 had the least solubility (fig. 2). Hence, T80 and SHS were taken for further studies.

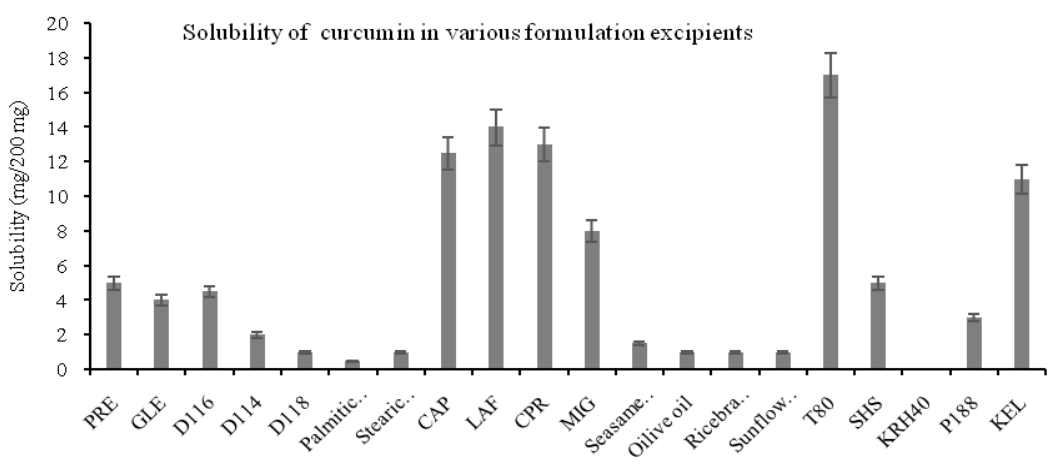

Fig. 2: Solubility of curcumin in formulation excipients

\section{Preliminary screening of formulation and process-related parameters}

The particle size decreased for solid lipids in the order of D116>D114 $>$ GLE $>$ D118 $>$ PRE. No relationship between the chemical structure of the lipids and particle size was observed. The formulations prepared by D114 and D118 lacked thermodynamic stability (drug leakage) and formulations with GLE and D116 showed phase separation. Hence, PRE was selected for the preparation of curcumin-loaded NLCs. Non-ionic emulsifiers (alone or in combination) showed better thermodynamic stability. A combination of emulsifiers is used to reduce the toxicity of individual emulsifier when reduced to half. A combination of T80 and SHS was used for further studies. It was observed that as the emulsifier concentration was increased, the particle size and PDI decreased. But after a certain concentration, the increase in emulsifier concentration did not show a significant reduction in particle size and PDI. Hence, $1.5 \%$ of the emulsifier concentration was selected. The least particle size and PDI were observed when the curcumin NLCs were subjected to 15 min of sonication. However, there is no considerate difference in the particle size and PDI obtained from 5 and 10 min sonication times and hence, 5 minute was selected as the sonication time for further series of experiments (table 3).

Table 3: Preliminary screening data for formulation and process-related parameters of curcumin loaded NLCs

\begin{tabular}{|c|c|c|c|c|c|c|c|c|}
\hline Variable & SL & $\mathbf{L L}$ & Emulsifier & EC & ST & Particle size (nm) & PDI & Thermodynamic stability \\
\hline \multirow[t]{5}{*}{ SL } & GLE & CAP & SHS & 1.5 & 10 & $284.0 \pm 8.5$ & 0.401 & No \\
\hline & PRE & CAP & SHS & 1.5 & 10 & $222.0 \pm 4.9$ & 0.345 & Yes \\
\hline & D114 & CAP & SHS & 1.5 & 10 & $317.0 \pm 46.7$ & 0.259 & No \\
\hline & D116 & CAP & SHS & 1.5 & 10 & $361.0 \pm 12.4$ & 0.355 & No \\
\hline & D118 & CAP & SHS & 1.5 & 10 & $272.0 \pm 71.5$ & 0.193 & No \\
\hline \multirow[t]{3}{*}{ Emulsifier } & PRE & CAP & SHS & 1.5 & 10 & $225.5 \pm 6.7$ & 0.322 & Yes \\
\hline & PRE & CAP & T80 & 1.5 & 10 & $170.4 \pm 3.4$ & 0.298 & Yes \\
\hline & PRE & CAP & SHS+T80 & 1.5 & 10 & $207.7 \pm 5.4$ & 0.237 & Yes \\
\hline \multirow[t]{3}{*}{ ST } & PRE & CAP & SHS+T80 & 1.5 & 5 & $219.5 \pm 8.4$ & 0.215 & Yes \\
\hline & PRE & CAP & SHS+T80 & 1.5 & 10 & $212.7 \pm 7.8$ & 0.208 & Yes \\
\hline & PRE & CAP & SHS+T80 & 1.5 & 15 & $189.9 \pm 3.1$ & 0.199 & Yes \\
\hline \multirow[t]{3}{*}{ EC } & PRE & CAP & SHS+T80 & 1.0 & 5 & $287.0 \pm 8.7$ & 0.333 & Yes \\
\hline & PRE & CAP & SHS+T80 & 1.5 & 5 & $208.0 \pm 5.4$ & 0.244 & Yes \\
\hline & PRE & CAP & SHS+T80 & 2.0 & 5 & $189.0 \pm 4.1$ & 0.206 & Yes \\
\hline
\end{tabular}

SL-Solid lipid, LL-Liquid lipid, EC-Emulsifier concentration, ST-Sonication time in min, PDI-Polydispersity index. 
Table 4: Responses observed in $2^{2}$ factorial design for curcumin loaded NLCs

\begin{tabular}{|c|c|c|c|c|c|c|c|}
\hline Standard & Run & \multicolumn{2}{|c|}{ Factor 1 A: EC (mg) } & \multicolumn{2}{|c|}{ Factor 2 B: ST (min) } & \multirow{2}{*}{$\begin{array}{l}\text { Response 1 PS (nm) } \\
234.90\end{array}$} & \multirow{2}{*}{$\begin{array}{l}\text { Response 2 PDI } \\
0.258\end{array}$} \\
\hline 4 & 1 & 1 & 170 & -1 & 2 & & \\
\hline 8 & 2 & 1 & 170 & 1 & 7 & 197.10 & 0.138 \\
\hline 3 & 3 & 1 & 170 & -1 & 2 & 218.90 & 0.238 \\
\hline 2 & 4 & -1 & 120 & -1 & 2 & 269.00 & 0.421 \\
\hline 1 & 5 & -1 & 120 & -1 & 2 & 285.20 & 0.397 \\
\hline 6 & 6 & -1 & 120 & 1 & 7 & 222.64 & 0.399 \\
\hline 5 & 7 & -1 & 120 & 1 & 7 & 234.04 & 0.331 \\
\hline 7 & 8 & 1 & 170 & 1 & 7 & 184.40 & 0.183 \\
\hline
\end{tabular}

EC-Emulsifier concentration, ST-Sonication time, PS-Particle size, PDI-Polydispersity index.

\section{Optimization (Design of experiment)}

The selected factors, surfactant concentration and sonication time influenced the particle size and PDI is quite evident from the results in table 4.

\section{Response 1: particle size}

The particle size of curcumin-loaded NLCs varied from 184.4 to 269 as was observed from the data in table 4 . Table 5 indicates the result of ANOVA provided by the software after feeding the response of particle size.

The following parameters were deduced by the software for this response Particle size:

- The F-value of the model was found to be 29.82 , which implied that the model was significant. There was only a $0.34 \%$ chance that an F-value this large could occur due to noise.

- The variables surfactant concentration and sonication time were indicated to play a significant role in influencing this response.

- The "Pred $\mathrm{R}^{2}$ " value of 0.8288 was in reasonable agreement with the "Adj R2" value of 0.9251 , i.e. the difference was less than 0.200 .

- The "Adeq precision" measures the signal-to-noise ratio. If this ratio is greater than 4 , then it is considered to be desirable. The ratio of 13.229 indicated an adequate signal. And hence, this model could be used to navigate the design space.

Equation derived for particle size: Particle size $=+229.52-20.7^{*}$ EC$22.48^{*} \mathrm{ST}+4.4^{*} \mathrm{EC}^{*} \mathrm{ST}$

The equation suggested that both factors have a negative effect on particle size. Negative value coefficients indicate that the particle size decreases with an increase in EC and ST. Hence, at a high level of both the factors, a smaller particle size could be obtained. When the coefficient values of two independent factors are compared, the value of the coefficient of sonication time (22.48) was found to be higher than that of the emulsifier concentration (20.7). Hence, it can be said that ST has more effect on particle size as compared to EC. However, there is not much difference in the coefficients of the two factors and both significantly affect the particle size.

\section{The pareto chart, contour and $3 D$ surface response plots for} particle size

The pareto chart also indicated the negative value of the two factors, EC and ST, and the positive value of the interaction. The coefficients of EC and ST with $t$ values above the bonferroni limit indicate that these are certainly significant coefficients and affect the response, whereas the coefficient of $\mathrm{AB}$ with $\mathrm{t}$ value below the limit is non-significant and not a major contributing factor to the response. Also, as observed from the equation, the coefficient of ST with a t value bigger than that of EC will affect particle size more than EC. The pareto chart for the response of particle size is represented in fig. 3A. The relationship between the factors and the responses was further elucidated using the contour and response surface plots. 3D response surface plots give a representation of the variations in each response when the two factors are simultaneously changed from a lower to a higher level. It gives a three-dimensional curvature of the change in response at different factor levels. It also gives the variation in design points from the predicted response value. Fig. 3B illustrates the contour plot indicating that the particle size decreased with an increase in surfactant concentration and sonication time. Similar observations were illustrated by the 3D surface response plot in fig. 3C.

\section{Response 2: polydispersity index}

The PDI of Curcumin NLCs varied from 0.138 to 0.421 as was observed from the data in table 4 . Table 5 indicated the results of ANOVA provided by the software after feeding the response of PDI.

The following parameters were deduced by the software for this response PDI:

- The F-value of the model was found to be 26.71, which implied that the model was significant. There was only a $0.42 \%$ chance that an F-value this large could occur due to noise.

- The variables surfactant concentration and sonication time were indicated to play a significant role in influencing this response.

- The "Pred $\mathrm{R}^{2}$ " value of 0.8099 was in reasonable agreement with

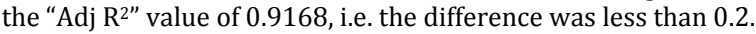

- The "Adeq precision" measures the signal-to-noise ratio. If this ratio is greater than 4 , then it is considered to be desirable. The ratio of 11.383 indicated an adequate signal. And hence, this model could be used to navigate the design space.

Equation derived for polydispersity index: PDI $=+0.3-0.091 *$ EC0.033* ST-0.011* EC * ST

PDI was shown to be significantly affected by emulsifier concentration and sonication time. PDI also tends to decrease with an increase in EC and ST. This was indicated by the negative value of the coefficients of the two factors. However, the values of coefficients indicate that surfactant concentration affects the response more significantly as compared to the sonication time, as the coefficient value of EC (0.091) is much higher than that of ST (0.033).

The pareto chart, contour and 3D surface response plots for the PDI

The pareto chart depicted that the coefficient of EC with $t$ value above the bonferroni line was certainly a significant coefficient and the coefficient of ST with t value between the bonferroni line and the t limit line was likely to be significant. Hence, it could be concluded that EC affected PDI more than ST. The pareto chart for the response PDI is illustrated in fig. 3D. The contour and 3D surface response plot also suggested that PDI decreased with an increase in EC and ST. The least PDI was observed with a high level of both factors. Fig. $3 \mathrm{E}$ and $3 \mathrm{~F}$ illustrate the contour and $3 \mathrm{D}$ surface response plots, respectively for the response PDI.

Table 5: Results of ANOVA for the response particle size and PDI

\begin{tabular}{llllll}
\hline Source & \multicolumn{2}{l}{ ANOVA for the response particle size } & \multicolumn{3}{l}{ ANOVA for the response PDI } \\
\cline { 2 - 6 } & F Value & p-value Prob>F & Outcome & F Value & p-value Prob>F \\
\hline Model & 29.82 & 0.0034 & Significant & 26.71 & 0.0042 \\
A-EC & 40.22 & 0.0032 & & 70.08 & 0.0011 \\
B-ST & 47.43 & 0.0023 & & 9.07 & 0.0395 \\
AB & 1.82 & 0.2487 & 0.99 & 0.3755 \\
\hline
\end{tabular}


The desirability plot suggests the region (working space) from which any formulation prepared would have resulted in the desired range of responses. The overlay plot takes into consideration all the desired values of responses and shows the area suitable by combining all the factors. In the desirability plot, it can be observed that at high levels of both surfactant concentration and sonication time, the formulation prepared would have the highest desirability 1 . The red-colored area depicts the working range for the optimized formulation. The yellow coloured region in the overlay plot depicts the working region for the optimized formulation. Fig. 4A depicts the desirability plot for the curcumin-loaded NLC formulation and fig. 4B depicts the overlay plot.

\section{Optimized curcumin loaded NLCs formulation}

For the point with emulsifier concentration and sonication time value 1,1 from the overlay plot, all the responses are predicted to be in the desired limit. Hence this formulation was selected as the optimized batch of the curcumin loaded NLCs. Hence high level of emulsifier concentration ( +1 ) was selected i.e. $170 \mathrm{mg}$ and high level of sonication time $(+1)$ i.e. 7 min was selected for preparation of optimized batch.

\section{Lyophilisation}

For screening of cryoprotectants, nanoparticles (fig. 5A) were subjected to freeze-thaw cycles of $12 \mathrm{~h}$ freezing and a $12 \mathrm{~h}$ drying cycle for a duration of three days. The results obtained from freeze thaw cycles were not very significant except that mannitol showed slightly better particle size as compared to others. Lactose tried during the freeze-thaw cycle showed an extreme increase in particle size; hence it was discontinued (table 6).
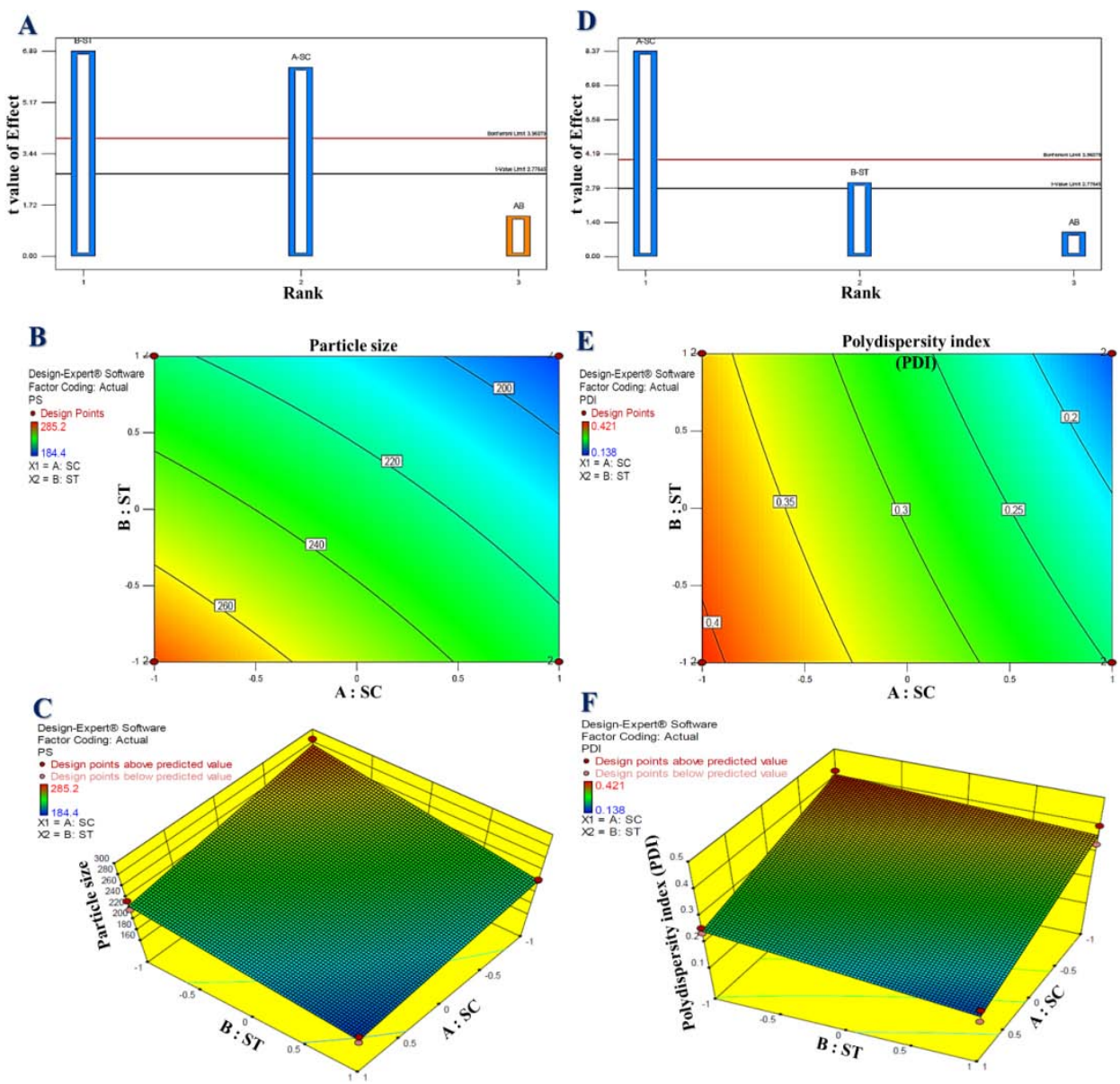

Fig. 3: Design of experiment charts for particle size (A. pareto chart, B. contour plot, C. 3D surface response plot) and PDI (D. pareto chart, E. contour plot, F. 3D surface response plot)

A

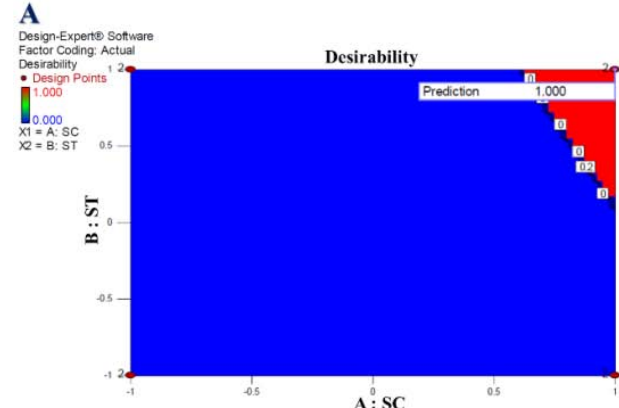

B

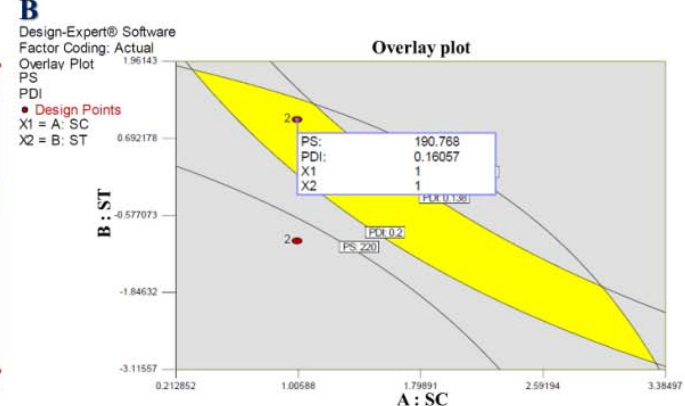

Fig. 4: A. Desirability and B. overlay plot 
Table 6: Screening of cryoprotectants for lyophilization

\begin{tabular}{|c|c|c|c|c|c|}
\hline Cryoprotectants & Concentration (\%) & Initial particle size (nm) & Particle size of redispersed NLCs (nm) & PDI & Sf/Si Ratio \\
\hline Placebo & -- & $205.4 \pm 12.3$ & $400.6 \pm 80.3$ & $0.491 \pm 0.085$ & 1.95 \\
\hline \multirow[t]{2}{*}{ Dextrose } & 7.00 & & $337.2 \pm 15.3$ & $0.242 \pm 0.021$ & 1.64 \\
\hline & 10.00 & & $568.0 \pm 98.5$ & $0.409 \pm 0.035$ & 2.77 \\
\hline \multirow[t]{3}{*}{ Mannitol } & 5.00 & & $286.2 \pm 11.5$ & $0.288 \pm 0.011$ & 1.39 \\
\hline & 8.00 & & $359.0 \pm 21.9$ & $0.324 \pm 0.055$ & 1.75 \\
\hline & 10.00 & & $400.0 \pm 22.4$ & $0.458 \pm 0.049$ & 1.95 \\
\hline
\end{tabular}

Cryoprotectants at $10 \% \mathrm{w} / \mathrm{v}$ concentration showed higher particle size. The particle size of cryoprotectants was in the order of mannitol<sucrose<dextrose at the highest concentration. The minimum difference in particle size and PDI before and after lyophilisation was observed in the case of mannitol $(5 \% \mathrm{w} / \mathrm{v})$ as the cryoprotective agent. Hence, mannitol $5 \%$ was chosen for the lyophilization of curcumin loaded NLCs (fig. 5B).

Characterization and evaluation of lyophilised dried curcumin loaded NLCs

\section{Redispersibility and drug content}

The formulation reconstituted easily within no time after the addition of water. The formulation was found to be easily redispersible with manual shaking. The drug content in the formulation was found to be $99.38 \pm 0.71 \%$. The chromatogram of the standard curcumin (fig. 6A) and curcumin in curcumin loaded NLC formulation (fig. 6B) was comparable. This shows that the drug does not undergo degradation when formulated in the form of NLCs.

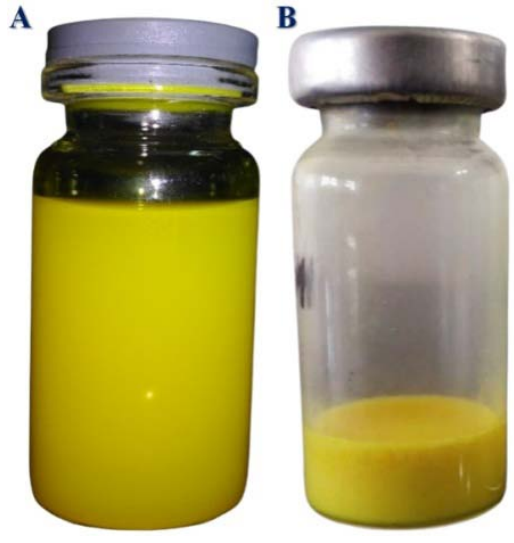

Fig. 5: A. Curcumin loaded NLCs, B. Lyophilized curcumin loaded NLCs
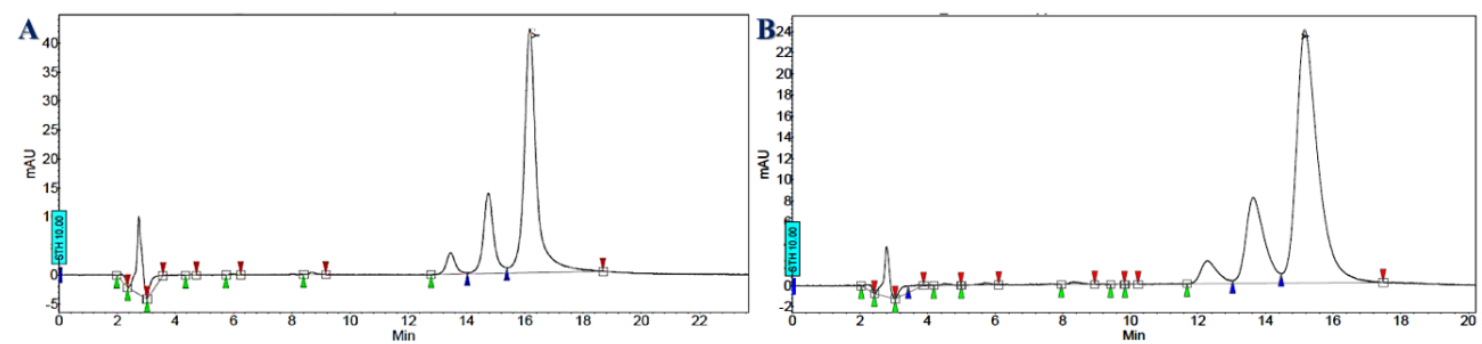

Fig. 6: Chromatogram of A. standard curcumin, B. curcumin in curcumin loaded NLCs

\section{Particle size, size distribution and zeta potential}

The particle size of the curcumin loaded NLCs dispersion was found to be $205.4 \pm 12.3 \mathrm{~nm}$ with a polydispersity index of $0.207 \pm 0.008$ whereas that of the optimized lyophilised curcumin loaded NLCs was found to be $286.5 \pm 11.5 \mathrm{~nm}$ and a PDI of $0.288 \pm 0.011$ respectively. The particle size and PDI of the NLCs tend to increase on lyophilisation. The Sf/Si ratio (ratio of nanoparticles size after and before lyophilization) of 1.39 was observed, which can be considered acceptable. Though the PDI of lyophilised products was increased, it was within the acceptable limit. The T80 and SHS stabilized NLC formulations had a zeta potential value of $0.063 \pm 0.002 \mathrm{mV}$ and thus an almost neutral surface charge. Both the emulsifiers are non-ionic and do not bear any charge. Hence, the particles did not show any surface charge on them. Also, the lyophilised formulation had a zeta potential value of $0.247 \pm 0.025$
$\mathrm{mV}$, which is not a very significant change. Hence, lyophilisation did not affect the zeta potential of the formulation.

\section{Entrapment efficiency and drug loading}

The entrapment of curcumin loaded NLCs was found to be $98.20 \pm 1.53 \%$ suggesting the maximum amount of drug entrapment in the NLCs. The drug loading of curcumin loaded NLCs was found to be $2.50 \pm 0.21 \%$.

\section{Surface morphology}

SEM studies suggest the spherical shape of the curcumin loaded NLCs with smooth surface morphology (fig. 7A). The adsorbent was found to be irregular in shape with aggregated masses. SEM of DANs showed adsorption of spherical NLCs on the surface of adsorbents. Also, the particle size observed using SEM was found to be in agreement with that obtained from the particle size analyser.

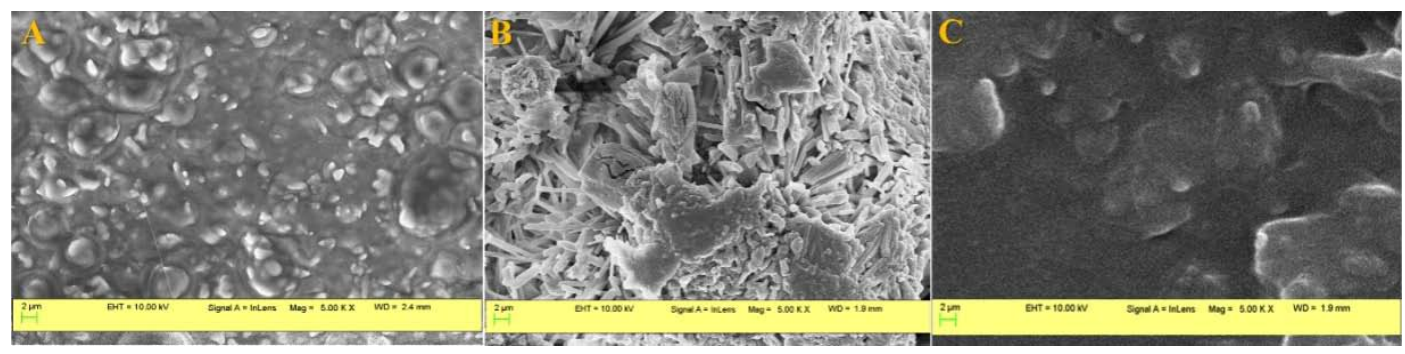

Fig. 7: Surface morphology of A. Curcumin loaded NLCs, B. Cryoprotectant mannitol and C. Lyophilized curcumin loaded NLCs 


\section{Crystallinity studies}

Curcumin showed sharp peaks at 8 and 17 along with some peaks of lower intensity. For the solid lipid PRE, broad peaks were observed. In a lyophilized curcumin-loaded NLCs formulation, the characteristic peaks of curcumin were absent (fig. 8). It indicated maximum solubilization of the curcumin within the lipid phase. But the thermogram showed additional peaks which might be due to the presence of cryoprotectant and the XRD studies confirmed the amorphous nature of the drug in NLCs.

\section{In vitro drug release studies}

For in vitro dissolution of a hydrophobic drug, sink conditions were to be maintained to achieve maximum release of the drug. The drug was poorly soluble in phosphate buffer saline; hence it was required to develop a dissolution medium allowing maximum solubility of the drug. In vitro drug release studies of curcumin loaded NLC formulations were performed to observe the amount of drug released and the pattern of drug release from the nanoparticles. It is an indicator of product performance. It was observed that $99.8 \pm 1.21$ $\%$ of standard curcumin was released at the end of $7 \mathrm{~h}$ whereas only $42.48 \pm 2.93 \%$ of the curcumin from the formulation was released at the same time. At the end of $24 \mathrm{~h}$ the drug release from the formulation was found to be $64.00 \pm 3.91 \%$. The drug release from standard curcumin was very fast, whereas the cumulative release rate from the formulation was much slower; an initial burst release was followed by a sustained release (fig. 9).

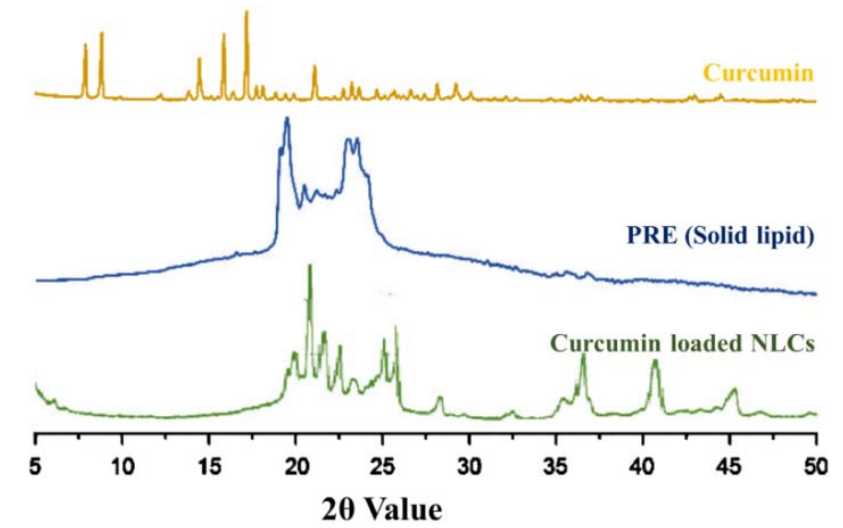

Fig. 8: X-ray diffractogram of standard curcumin, PRE (solid lipid) and curcumin loaded NLCs

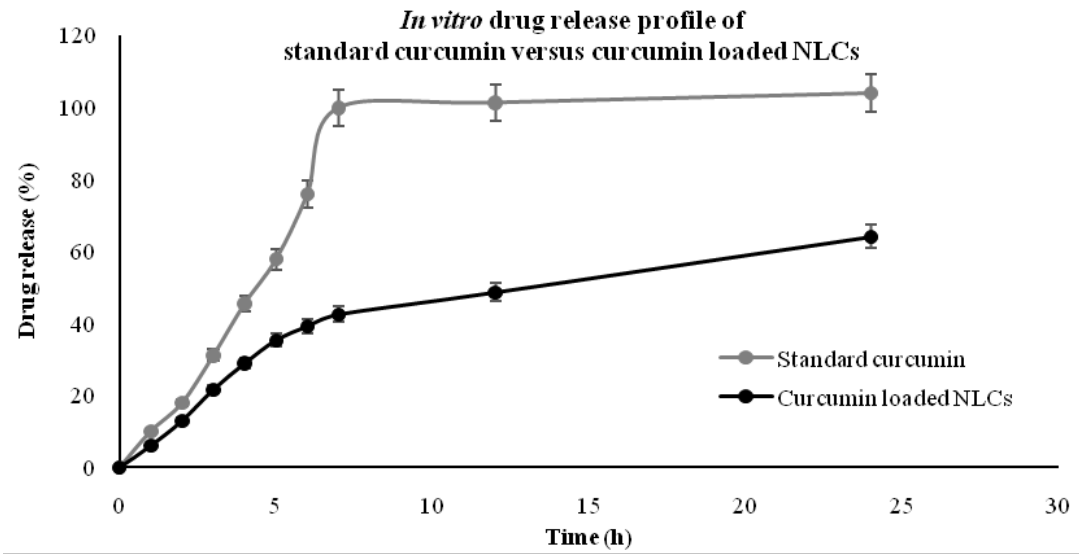

Fig. 9: In vitro drug release profile of standard curcumin versus curcumin loaded NLCs
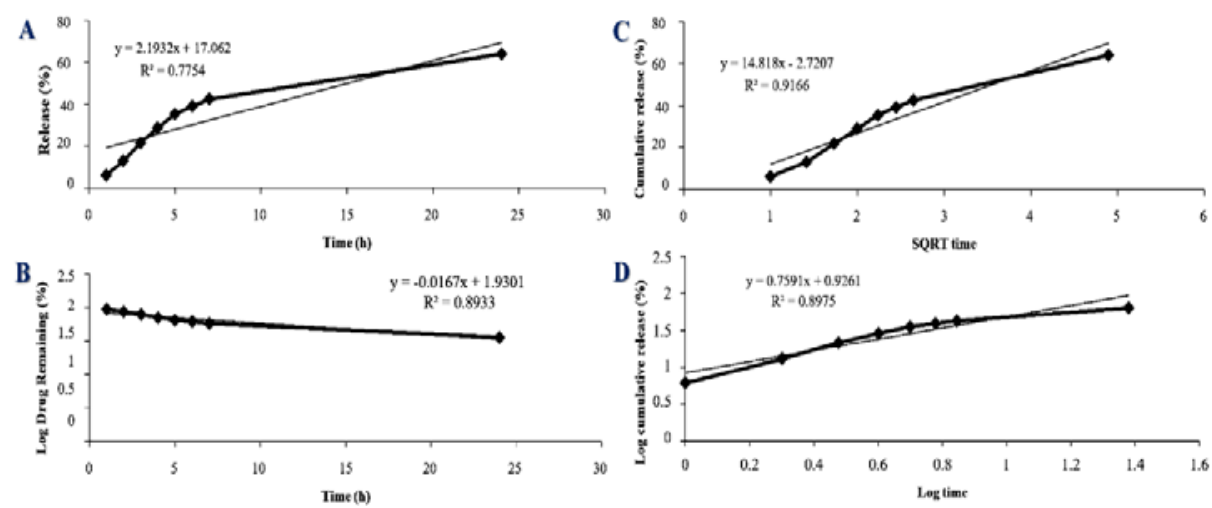

Fig. 10: Release kinetics of curcumin loaded NLCs A. Zero-order release, B. First-order release, C. Higuchi release and D. Korsmeyerpeppas 
Table 7 enlists the linearity coefficients obtained from different kinetic plots of in vitro drug release studies (fig. 10). From the linearity coefficient, it can be concluded that the curcumin-loaded NLCs formulation follows the higuchi model for drug release. The higuchi release kinetic model suggests that diffusion is one of the major methods of drug release and the drug release is unidirectional. As per korsemeyer-peppas, $\mathrm{n}$ was found to be 0.501 . This indicates the formulation follows non-fickian diffusion.

Table 7: Coefficient $\left(\mathrm{R}^{2}\right)$ values from different kinetic plots for curcumin loaded NLCs

\begin{tabular}{ll}
\hline Kinetic model & Linearity $\left(\mathbf{R}^{2}\right)$ \\
\hline Zero order & 0.775 \\
First order & 0.893 \\
Higuchi model & 0.916 \\
Korsmeyer-peppas model & $\mathrm{R}^{2}=0.897$ \\
& $\mathrm{n}=0.501$ \\
\hline
\end{tabular}

\section{In vitro cytotoxicity study for curcumin loaded NLCs}

Table 8 mentions the drug concentration of samples showing \% control growth and the growth curve of samples against the A-549, respectively. Fig. 11 illustrates images showing cell cytotoxicity of samples against A-549 cell line. Fig. 12 represents the \% control growth and the growth curve, and table 9 enlists the LC50, TGI, and
GI50 values of the samples calculated from the graph. Growth percent of 100 corresponded to growth seen in untreated cells. Growth percent of 0 indicated no net growth over the course of the assay (i.e. equal to the number of cells at time zero). Growth percent of-100 resulted when all cells were killed. Three endpoints were routinely calculated: 1) GI50, the log M concentration yielding a growth percent of 50 (i.e. $50 \%$ growth inhibition), 2) TGI, the log M concentration yielding a growth percent of 0 , or total growth inhibition, and 3) LC50, the $\log \mathrm{M}$ concentration yielding a growth percent of-50, or lethality in $50 \%$ of the starting cells. From the graph, it could be observed that the curcumin loaded NLC formulation showed a maximum decrease in percent growth of the cells. curcumin in DMSO was almost as efficient as the positive control. Curcumin in water showed no or very little decline in percent cell growth as the drug is very poorly soluble in water and hence might not be available for causing the desired activity. The NLCs formulation and ADR showed TGI, GI50 and LC50 at concentrations below $10 \mu \mathrm{g} / \mathrm{ml}$. The curcumin in DMSO showed LC50 and TGI at concentrations above 40 $\mu \mathrm{g} / \mathrm{ml}$. The results obtained from curcumin in water were not equivalent though, as suggested by the studies. This result could be due to less solubility of the compound. GI50 value of $\leq 10^{\wedge-6}$ mol (i.e. 1 $\mu \mathrm{mol}$ ) or $\leq 10 \mu \mathrm{g} / \mathrm{ml}$ was considered to demonstrate activity in the case of pure compounds. Hence, it could be concluded that curcumin loaded NLC formulation, curcumin suspended in water and curcumin in DMSO all showed activity against the cell lines. Hence, finally, it can be concluded that curcumin-loaded NLCs showed improved effectiveness in preventing cell growth as compared to curcumin in water and DMSO.

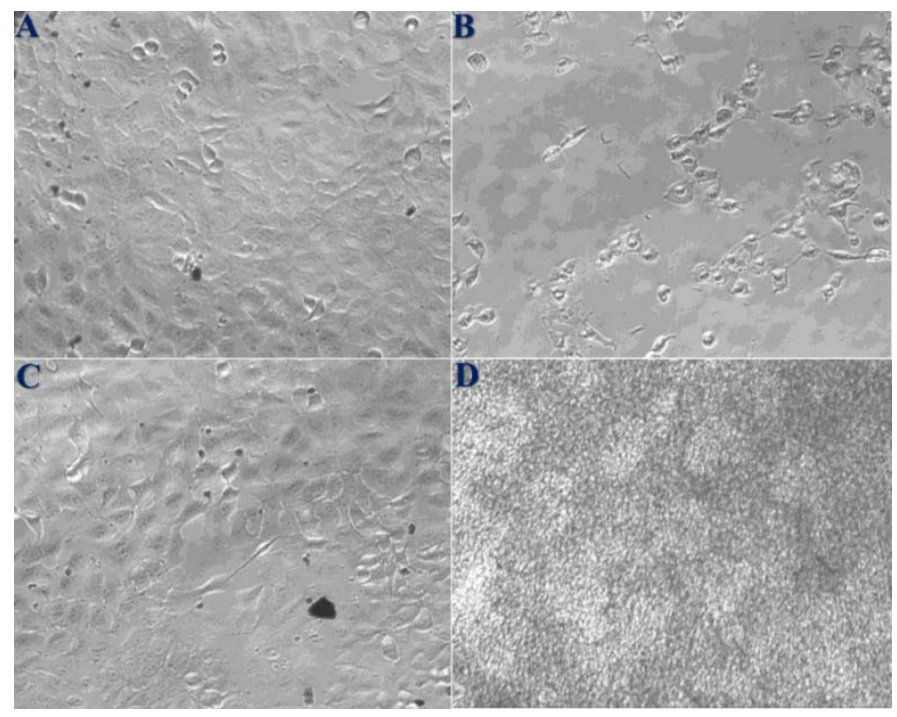

Fig. 11: Cell cytotoxicity of samples against A-549 cell line A. Curcumin loaded NLCs (formulation), B. Curcumin in water, C. Curcumin in DMSO and D. A-549 positive control (ADR)

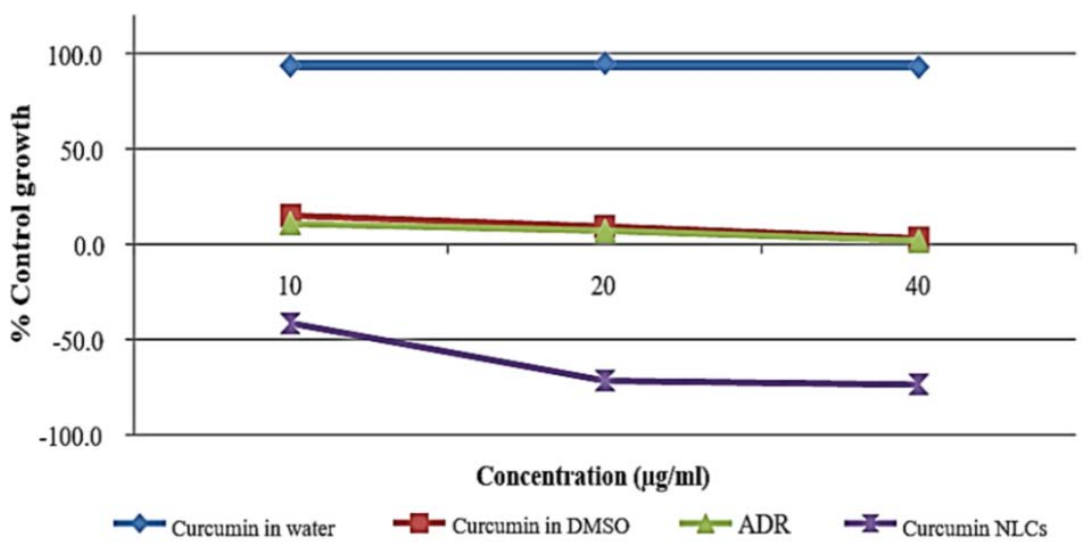

Fig. 12: Growth curve of samples against A-549-Curcumin in water, curcumin in DMSO, ADR and curcumin loaded NLCs 
Table 8: In vitro \% control growth in human lung cancer line A-549

\begin{tabular}{|c|c|c|c|c|c|c|c|c|c|c|c|c|}
\hline \multirow{2}{*}{$\begin{array}{l}\text { Samples } \\
\text { Curcumin concentration }(\mu \mathrm{g} / \mathrm{ml})\end{array}$} & \multicolumn{3}{|c|}{ Experiment 01} & \multicolumn{3}{|c|}{ Experiment 02} & \multicolumn{3}{|c|}{ Experiment 03} & \multicolumn{3}{|c|}{ Average } \\
\hline & 10 & 20 & 40 & 10 & 20 & 40 & 10 & 20 & 40 & 10 & 20 & 40 \\
\hline Curcumin loaded NLCs & -19.5 & -68.5 & -74.8 & -34.4 & -75.7 & -73.3 & -70.8 & -70.5 & -72.9 & -41.6 & -71.5 & -73.7 \\
\hline Curcumin in water & 95.2 & 91.1 & 90.1 & 91.0 & 94.7 & 92.2 & 93.8 & 99.1 & 96.5 & 93.3 & 95.0 & 92.9 \\
\hline Curcumin in DMSO & 22.7 & 9.3 & 2.4 & 10.99 & 9.2 & 2.3 & 11.0 & 9.0 & 4.2 & 14.9 & 9.1 & 3.0 \\
\hline ADR (Control) & 26.4 & 15.1 & 2.1 & 3.5 & 2.8 & 2.1 & 2.3 & 3.0 & 1.6 & 10.7 & 7.0 & 1.9 \\
\hline
\end{tabular}

Table 9: LC50, TGI and GI50 values of the samples

\begin{tabular}{llll}
\hline Drug concentrations $(\boldsymbol{\mu g} / \mathbf{m l})$ calculated from graph & & TGI \\
\hline A-549 cell line & LC50 & $<10$ & $<10$ \\
Curcumin loaded NLCs & $<10$ & Not equivalent & Not equivalent \\
Curcumin in water & Not equivalent & $>40$ & $<10$ \\
Curcumin in DMSO & $>40$ & $<10$ & $<10$ \\
ADR (Control) & $<10$ & & \\
\hline
\end{tabular}

\section{Real-time stability studies}

The stability study results suggested that the formulation was quite stable for the study duration of $60 \mathrm{~d}$. There were no significant changes in the particle size, PDI, and zeta potential. Also, the appearance was similar to that observed on the initial day. The formulation was easily redispersible throughout the batches. There was a slight decrease in entrapment efficiency with time. The percentage assay was also observed to have decreased slightly with increased time duration, although no signs of drug degradation were observed. This was confirmed by the absence of any degradation peaks in the chromatograms. The in vitro release profile of the formulation suggested a constant release pattern of the drug by indicating the stability of the NLC formulation (fig. 13). It was observed that the formulation was more stable when kept in refrigerated conditions as compared to room temperature. Although the difference was not substantial (table 10). All the parameters were within acceptable limits, which showed that the formulations were stable over a period of $60 \mathrm{~d}$. The results of stability studies indicated that the formulation had reasonable stability and would be acceptable for regulatory submissions where stability is paramount for any formulation.
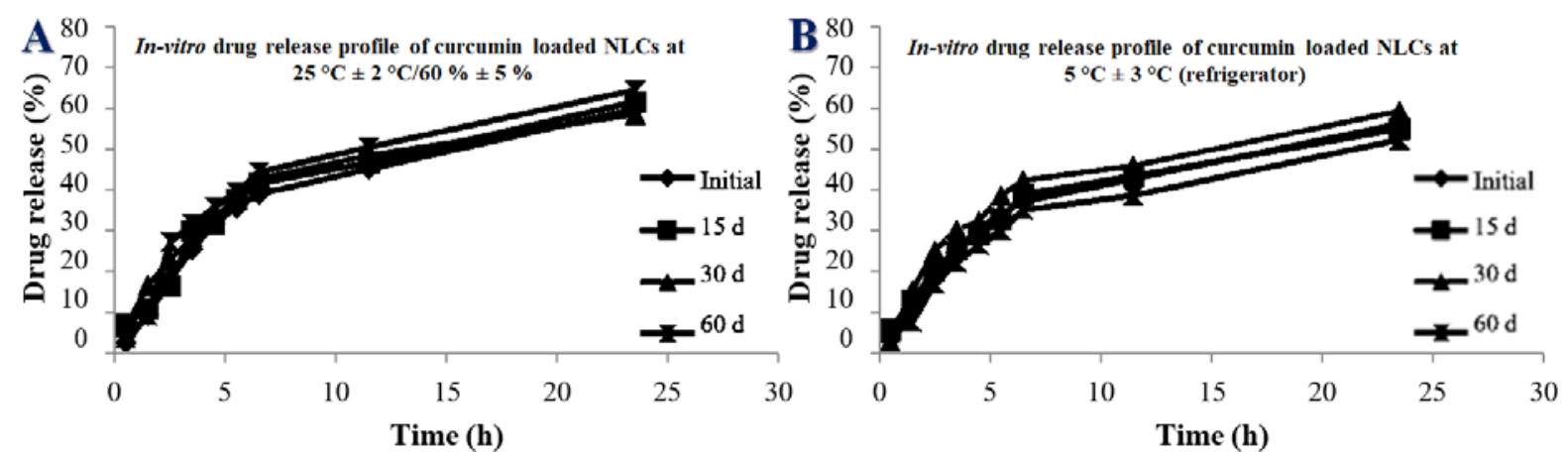

Fig. 13: In vitro drug release profile of curcumin loaded NLCs stability at $25^{\circ} \mathrm{C} \pm 2{ }^{\circ} \mathrm{C} / 60 \% \pm 5 \% \mathrm{RH}$ and $5{ }^{\circ} \mathrm{C} \pm 3{ }^{\circ} \mathrm{C}$ (refrigerator)

Table 10: Stability data of curcumin loaded NLCs subjected to $25{ }^{\circ} \mathrm{C} \pm 2{ }^{\circ} \mathrm{C} / 60 \% \pm 5 \% \mathrm{RH}$ and $5{ }^{\circ} \mathrm{C} \pm 3{ }^{\circ} \mathrm{C}$ (refrigerator)

\begin{tabular}{|c|c|c|c|c|c|c|c|}
\hline \multirow[t]{2}{*}{ Parameter } & \multirow{2}{*}{$\begin{array}{l}\text { RT } \\
\text { Initial } \\
\end{array}$} & \multicolumn{3}{|c|}{$25{ }^{\circ} \mathrm{C} \pm 2{ }^{\circ} \mathrm{C} / 60 \% \pm 5 \% \mathrm{RH}$} & \multicolumn{3}{|c|}{$5^{\circ} \mathrm{C} \pm 3^{\circ} \mathrm{C}$ (refrigerator) } \\
\hline & & $15 \mathrm{~d}$ & $30 \mathrm{~d}$ & $60 \mathrm{~d}$ & $15 \mathrm{~d}$ & $30 \mathrm{~d}$ & $60 \mathrm{~d}$ \\
\hline Redispersibility & Excellent & Excellent & Excellent & Excellent & Excellent & Excellent & Excellent \\
\hline Particle size (nm) & $286.2 \pm 11.5$ & $289.8 \pm 12.5$ & $299.8 \pm 14.7$ & $295.4 \pm 18.4$ & $288.2 \pm 7.9$ & $285.5 \pm 13.7$ & $290.7 \pm 14.5$ \\
\hline PDI & $0.288 \pm 0.011$ & $0.294 \pm 0.035$ & $0.305 \pm 0.018$ & $0.313 \pm 0.028$ & $0.285 \pm 0.017$ & $0.290 \pm 0.015$ & $0.298 \pm 0.041$ \\
\hline Zeta potential $(\mathrm{mV})$ & $0.247 \pm 0.025$ & $0.299 \pm 0.015$ & $0.314 \pm 0.034$ & $0.302 \pm 0.019$ & $0.286 \pm 0.041$ & $0.305 \pm 0.025$ & $0.309 \pm 0.015$ \\
\hline In vitro drug release (\%) & $64.0 \pm 3.91$ & $65.09 \pm 2.89$ & $62.00 \pm 2.45$ & $68.93 \pm 1.45$ & $56.02 \pm 8.31$ & $67.74 \pm 4.34$ & $59.11 \pm 3.24$ \\
\hline $\mathrm{EE}(\%)$ & $98.20 \pm 1.53$ & $97.97 \pm 0.97$ & $97.90 \pm 1.14$ & $97.82 \pm 0.79$ & $98.04 \pm 1.45$ & $97.93 \pm 1.34$ & $97.90 \pm 1.54$ \\
\hline Drug content $(\%)$ & $99.38 \pm 0.71$ & $98.6 \pm 0.19$ & $98.53 \pm 0.15$ & $98.59 \pm 0.25$ & $98.59 \pm 0.11$ & $98.59 \pm 0.34$ & $98.54 \pm 0.45$ \\
\hline
\end{tabular}

The curcumin showed maximum solubility in PRE. Chemically, PRE and GLE are mixtures of fatty acid esters and monoglycerides, respectively. This decreases the chances of crystallization of lipids into various polymeric forms and thus can encapsulate the maximum amount of curcumin. Further, dynasans $(114,116$ and 118) are highly crystalline in nature, which shows minimum solubility for curcumin and limits their encapsulation efficiency [33, 34]. The stability of lipid nanoparticles can be improved by incorporating liquid lipid (oil component) as it can control crystal structure. The LAF showed the maximum solubility for curcumin.
The encapsulation efficiency can be easily improved by liquid lipids due to the higher solubility of curcumin in liquid lipids. Further, the stability of the system can be improved as the surface tension of oil droplets can be controlled better with surfactants, which helps to maintain a smaller particle size in the system [35]. The incorporation of emulsifiers helps to reduce particle aggregation, which improves the stability of the system. The combination of nonionic surfactants T80 and SHS were used in curcumin-loaded NLCs, which maintains the balance of crystallization by repelling forces. This helps to maintain the stability of the lipid nanoparticles during 
the shelf life [36]. The higher emulsifier concentrations provide enough emulsifiers to cover the tiny lipid particles which stabilize and prevent the coalescence of nanoparticles. The lipid systems with low emulsifier concentration lead to aggregation of lipid particles due to hydrophobic attraction between insufficiently covered lipid crystal surfaces [37-39]. The results show that the higher emulsifier concentration of $2 \%$ produced NLCs with a $200 \mathrm{~nm}$ with a very narrow size distribution $(0.200)$. The surfactant concentration was limited to $1.7 \%$ to avoid toxicity. The particle size and its size distribution can be decreased by increasing the sonication time. The ultrasonication helps to breakdown the coarser lipid particles to the nanoscale. Thus, increased sonication time provides more energy which provides shear stresses and breaks down the particles size. Further, increased sonication time also provides the production of nanoparticles with a very narrow size distribution [40]. The results obtained were in accordance with the published literature. The sonication time of more than 10 min resulted in a particle size less than $200 \mathrm{~nm}$ with a size distribution less than 0.200 . The lyophilized curcumin loaded NLCs showed a slight increase in particle size after Redispersion may be due to the agglomeration of nanoparticles. This could be attributed to the stresses associated with freezing, resulting in a measurable increase in particle size $[39,41]$. However, the redispersed curcumin-loaded NLCs resulted in a particle size of $286.2 \pm 11.5 \mathrm{~nm}$ with a size distribution of $0.288 \pm 0.011$, which is considered not a significant difference from standard curcumin loaded NLCs. Further, it was reported that nanoparticles reach the target site by capillary distribution. These particles can easily cross vascular endothelia and accumulate at the target tumour site by enhanced permeation and retention effects [42]. The hydrophilic polyethylene oxide chains in the T80 provide the stabilizing effect through stearic repulsion. These chains are presumed to form a shell around the nanoparticles that sterically prevents the nanoparticles from aggregation [10]. The release of curcumin from NLCs dispersion was only $42.48 \pm 2.93 \%$ in comparison with standard curcumin suspension of $99.80 \pm 1.21 \%$ at $7 \mathrm{~h}$. The initial rapid release may be due to the release of curcumin from liquid lipids and from NLCs surface and whereas the sustained release characteristics suggest the diffusion of drugs from the core of the lipid matrix. Sustained release from NLCs may result in prolonged exposure of tumour cells to this drug, increasing clinical efficacy. The initial rapid release of drug from the nanoparticles is attributed to the drug enriched oil droplets located on the outer surface of the nanoparticles. The higher melting point of the solid lipid core provides a sustained release matrix for drugs [23]. The curcumin loaded NLCs in the present study showed significant cytotoxicity in comparison with the positive control ADR. The cytotoxic effect of curcumin loaded NLCs is exhibited by a pro-apoptotic effect [22]. The half-maximal inhibitory concentration (IC50) values in the present study showed less than $10 \mu \mathrm{g} / \mathrm{ml}$ for curcumin loaded NLC and ADR (control). The higher IC50 value for curcumin in water may be attributed to the insoluble nature of curcumin in the desired medium. The obtained results were supported by various previously published literature. Madane and Mahajan et al. reported that the increased cytotoxic effect of curcumin loaded NLCs against the gliblastoma cell line. The IC50 values were reported to be $9.8 \mathrm{ng} / \mathrm{ml}$ for curcumin loaded NLCs and $13.6 \mathrm{ng} / \mathrm{ml}$ for ADR (control) [23]. The study of cellular uptake and anticancer efficiency against brain cancer for curcumin NLCs showed an IC50 of $20 \mathrm{mg} / \mathrm{ml}$ which is four times less than standard curcumin. Further, plasmid concentration showed a 6.4-fold increase in curcumin concentrations when administered in the NLCs system and inhibitory efficiency increased from $19.5 \%$ to $82.3 \%$ over plan curcumin than in curcumin loaded NLCs [25]. Another study reported that the cytotoxic effect of curcumin loaded NLCs on Hela cells was due to the ability of NLCs to attach and pass through the cell membranes, inducing apoptosis, inhibiting cell proliferation and also inhibiting telomerase activity [27]. The cytotoxicity against human lung adenocarcinoma A549 cells showed a higher apoptosis rate for curcumin loaded NLCs than standard curcumin. The reported IC 50 value of $5.66 \mathrm{mg} / \mathrm{l}$ for curcumin loaded NLCs and $9.81 \mathrm{mg} / \mathrm{l}$ for standard curcumin [28].

\section{CONCLUSION}

The optimized curcumin loaded NLCs were developed by a modified hot melt emulsification with maximum entrapment efficiency, drug loading, nano particle size distribution and zeta potential. The optimized curcumin loaded NLCs consist of PRE as a solid lipid, CAP as a liquid lipid and a combination of T80 and SHS as surfactants. The impact of formulation and process parameters were investigated by a systematic approach in terms of thermodynamic stability, particle size, size distribution, and entrapment efficiency. Further, the thermodynamic stability of the NLCs dispersion was improved by lyophilisation using $5 \%$ mannitol as a cryoprotectant. The redispersed curcumin loaded NLCs have similar properties as those of the curcumin loaded NLC dispersion. The optimized NLC formulation has a sustained release profile for curcumin. The curcumin loaded NLCs had significant cytotoxic activity against human lung cancer line A-549 with Adriamycin as a positive control. The developed, optimized lyophilized formulation can be further filled into sachets and capsules for oral administration.

\section{ABBREVIATION}

NLCs-Nanostructured lipid carriers, PRE-Precirol ATO 5, CAPCapmul MCM C8 EP, T80-Tween 80, SHS-Solutol HS 15, EEEntrapment efficiency, ADR-Adriamycin, GLE-Geleole, CPR-Capryol PGMC, D114-Dynasan 114 D116-Dynasan 116, D118-Dynasan 118, MIG-Miglyol 812, P188-Polaxomer 188, KEL-Kolliphore EL, KRH40Kolliphore RH 40, HPLC-High-performance liquid chromatography, EC-Emulsifier concentration, ST-Sonication time, PDI-Polydispersity index, ANOVA-Analysis of variance, SEM-Scanning electron microscopy, XRD-X-ray diffractogram, MPD-Multi-purpose diffractometer DMSO-Dimethyl sulfoxide, LC50-Concentration of drug causing $50 \%$ cell kill, GI50-Concentration of drug causing $50 \%$ inhibition of cell growth, TGI-Concentration of drug causing total inhibition of cell growth, ICH-International council for harmonisation, RH-Relative humidity, IC50-The half maximal inhibitory concentration, ACTREC-The Advanced Centre for Treatment, Research and Education in Cancer.

\section{ACKNOWLEDGMENT}

The authors also thank VAV Life Sciences, India for a gift sample of curcumin and also Gattefosse, India, and Cremer Oleo GmbH and Co. Germany, Indchem International, Mumbai. BASF, India, DFE Pharma, India., Signet, India for providing excipients as gift samples. The authors also sincerely thank Professor Mala Menon from Bombay college of Pharmacy, Mumbai for conducting the lyophilisation process. Our special thanks to the Advanced Centre for Treatment, Research and Education in Cancer (ACTREC), Tata Memorial Centre, Navi-Mumbai, India for carrying out in vitro cytotoxic studies.

\section{FUNDING}

The authors sincerely thank the All India Council for Technical Education (AICTE) [8-159/RIFD/RPS/Policy-4/2013-14] for financially supporting this work.

\section{AUTHORS CONTRIBUTIONS}

All the authors have contributed equally.

\section{CONFLICT OF INTERESTS}

\section{Declared none}

\section{REFERENCES}

1. Gupta SC, Patchva S, Aggarwal BB. Therapeutic roles of curcumin: lessons learned from clinical trials. AAPS J. 2013;15(1):195-218. doi: 10.1208/s12248-012-9432-8, PMID 23143785.

2. Allegra A, Innao V, Russo S, Gerace D, Alonci A, Musolino C. Anticancer activity of curcumin and its analogues: preclinical and clinical studies. Cancer Invest. 2017;35(1):1-22. doi: 10.1080/07357907.2016.1247166, PMID 27996308.

3. Shanmugam MK, Rane G, Kanchi MM, Arfuso F, Chinnathambi A, Zayed ME, Alharbi SA, Tan BK, Kumar AP, Sethi G. The multifaceted role of curcumin in cancer prevention and treatment. Molecules. 2015;20(2):2728-69. doi: 10.3390/ molecules20022728, PMID 25665066.

4. Kunwar A, Barik A, Mishra B, Rathinasamy K, Pandey R, Priyadarsini KI. Quantitative cellular uptake, localization and cytotoxicity of curcumin in normal and tumor cells. Biochim 
Biophys Acta. 2008;1780(4):673-9. doi: 10.1016/ j.bbagen. 2007.11.016, PMID 18178166.

5. Syng-Ai C, Kumari AL, Khar A. Effect of curcumin on normal and tumor cells: role of glutathione and bcl-2. Mol Cancer Ther. 2004;3(9):1101-8. PMID 15367704.

6. Ravindran J, Prasad S, Aggarwal BB. Curcumin and cancer cells: how many ways can curry kill tumor cells selectively? AAPS J. 2009;11(3):495-510. doi: 10.1208/s12248-009-9128-x, PMID 19590964.

7. Shoba G, Joy D, Joseph T, Majeed M, Rajendran R, Srinivas PS. Influence of piperine on the pharmacokinetics of curcumin in animals and human volunteers. Planta Med. 1998;64(4):353-6. doi: 10.1055/s-2006-957450, PMID 9619120.

8. Sharma RA, Steward WP, Gescher AJ. Pharmacokinetics and pharmacodynamics of curcumin. Adv Exp Med Biol. 2007;595:453-70. doi: 10.1007/978-0-387-46401-5_20, PMID 17569224.

9. Shen L, Ji HF. The pharmacology of curcumin: is it the degradation products? Trends Mol Med. 2012;18(3):138-44. doi: 10.1016/j.molmed.2012.01.004, PMID 22386732.

10. Ghorpade K, Shinde S. Design and development of curcumin loaded nanostructured lipid carriers for solubility enhancement. Int J Curr Res. 2019;11(1):20-6.

11. Sadati Behbahani ES, Ghaedi M, Abbaspour M, Rostamizadeh K, Dashtian K. Curcumin loaded nanostructured lipid carriers: in vitro digestion and release studies. Polyhedron. 2019;164:11322. doi: 10.1016/j.poly.2019.02.002.

12. Fang M, Jin $Y$, Bao W, Gao H, Xu M, Wang D, Wang X, Yao P, Liu $\mathrm{L}$. In vitro characterization and in vivo evaluation of nanostructured lipid curcumin carriers for intragastric administration. Int J Nanomedicine. 2012;7:5395-404. doi: 10.2147/IJN.S36257, PMID 23091382.

13. Chen P, Zhang H, Cheng S, Zhai G, Shen C. Development of curcumin loaded nanostructured lipid carrier based thermosensitive in situ gel for dermal delivery. Colloids and Surfaces A: Physicochemical and Engineering Aspects. 2016;506:356-62. doi: 10.1016/j.colsurfa.2016.06.054.

14. Rapalli VK, Kaul V, Waghule T, Gorantla S, Sharma S, Roy A, Dubey SK, Singhvi G. Curcumin loaded nanostructured lipid carriers for enhanced skin retained topical delivery: optimization, scale-up, in-vitro characterization and assessment of ex-vivo skin deposition. Eur J Pharm Sci. 2020;152:105438. doi: 10.1016/j.ejps.2020.105438, PMID 32598913.

15. Esposito E, Ravani L, Mariani P, Huang N, Boldrini P, Drechsler M, Valacchi G, Cortesi R, Puglia C. Effect of nanostructured lipid vehicles on percutaneous absorption of curcumin. Eur J Pharm Biopharm. 2014;86(2):121-32. doi: 10.1016/j.ejpb. 2013. 12.011, PMID 24361485.

16. Lee HJ, Jeong M, Na YG, Kim SJ, Lee HK, Cho CW. An EGF- and curcumin-co-encapsulated nanostructured lipid carrier accelerates chronic-wound healing in diabetic rats. Molecules. 2020;25(20):114. doi: 10.3390/molecules25204610, PMID 33050393.

17. Rabima R, Oktamauri A. Characterization and antibacterial activity of curcumin-nanostructured lipid carrier. Indones Nat Res Pharm J 2019;3(2):1-10.

18. Sadegh Malvajerd S, Izadi Z, Azadi A, Kurd M, Derakhshankhah H, Sharifzadeh M, Akbari Javar H, Hamidi M. Neuroprotective potential of curcumin-loaded nanostructured lipid carrier in an animal model of Alzheimer's disease: behavioral and biochemical evidence. J Alzheimers Dis. 2019;69(3):671-86. doi: 10.3233/JAD-190083, PMID 31156160.

19. Lakhani P, Patil A, Taskar P, Ashour E, Majumdar S. Curcuminloaded nanostructured lipid carriers for ocular drug delivery: design optimization and characterization. J Drug Deliv Sci Technol. 2018;47:159-66. doi: 10.1016/j.jddst.2018.07.010, PMID 32601526.

20. Yoozbashi M, Rashidzadeh $H$, Kermanian M, Sadighian S, Hosseini M, Kaboli Z, Rostamizadeh K. Magnetic nanostructured lipid carrier for dual triggered curcumin delivery: Preparation, characterization and toxicity evaluation on isolated rat liver mitochondria. J Biomater Appl. 2021 Jul;28: $\quad 8853282211034625$. doi: 10.1177/ 08853282211034625 .
21. Meng F, Asghar S, Xu Y, Wang J, Jin X, Wang Z, Wang J, Ping Q, Zhou J, Xiao Y. Design and evaluation of lipoprotein resembling curcumin-encapsulated protein-free nanostructured lipid carrier for brain targeting. Int J Pharm. 2016;506(1-2):46-56. doi: 10.1016/j.ijpharm.2016.04.033, PMID 27094357.

22. Wang F, Ye X, Zhai D, Dai W, Wu Y, Chen J, Chen W. Curcuminloaded nanostructured lipid carrier induced apoptosis in human HepG2 cells through activation of the DR5/caspasemediated extrinsic apoptosis pathway. Acta Pharm. 2020;70(2):227-37. doi: 10.2478/acph-2020-0003, PMID 31955141.

23. Madane RG, Mahajan HS. Curcumin-loaded nanostructured lipid carriers (NLCs) for nasal administration: design, characterization, and in vivo study. Drug Deliv. 2016;23(4):1326-34. doi: 10.3109/10717544.2014.975382, PMID 25367836.

24. Chanburee S, Tiyaboonchai W. Enhanced intestinal absorption of curcumin in Caco-2 cell monolayer using mucoadhesive nanostructured lipid carriers. J Biomed Mater Res B Appl Biomater. 2018;106(2):734-41. doi: 10.1002/jbm.b.33884, PMID 28323388.

25. Chen Y, Pan L, Jiang M, Li D, Jin L. Nanostructured lipid carriers enhance the bioavailability and brain cancer inhibitory efficacy of curcumin both in vitro and in vivo. Drug Deliv. 2016;23(4):138392. doi: 10.3109/10717544.2015.1049719, PMID 26066035.

26. Kamel AE, Fadel M, Louis D. Curcumin-loaded nanostructured lipid carriers prepared using $\mathrm{Peceol}^{\mathrm{TM}}$ and olive oil in photodynamic therapy: development and application in breast cancer cell line. Int J Nanomedicine. 2019;14:5073-85. doi: 10.2147/IJN.S210484, PMID 31371948.

27. Rabima OA, Oktamauri A. Characterisation and cytotoxicity assay of curcumin nanostructured lipid carrier on HeLa cells. IOP Conf Ser: Earth Environ Sci. 2021;667(1):1-8. doi: 10.1088/1755-1315/667/1/012055.

28. Wang F, Chen J, Dai W, He Z, Zhai D, Chen W. Pharmacokinetic studies and anticancer activity of curcumin-loaded nanostructured lipid carriers. Acta Pharm. 2017;67(3):357-71. doi: 10.1515/acph-2017-0021, PMID 28858837.

29. Arora R, Katiyar SS, Kushwah V, Jain S. Solid lipid nanoparticles and nanostructured lipid carrier-based nanotherapeutics in treatment of psoriasis: a comparative study. Expert Opin Drug Deliv. 2017;14(2):165-77.

doi: 10.1080/17425247.2017.1264386, PMID 27882780.

30. Jain S, Cherukupalli SK, Mahmood A, Gotantla S, Rapalli VK, Dubey SK. Emerging nanoparticulate systems: preparation techniques and stimuli responsive release characteristics. J App Pharm Sci. 2019;9(8):130-43. doi: 10.7324/JAPS.2019.90817.

31. Sonawane R, Harde H, Katariya M, Agrawal S, Jain S. Solid lipid nanoparticles-loaded topical gel containing combination drugs: an approach to offset psoriasis. Expert Opin Drug Deliv. 2014;11(12):1833-47. doi: 10.1517/17425247.2014.938634, PMID 25078031.

32. Panigrahi S, Hirlekar R. A new stability-indicating RP-HPLC method for determination of curcumin: an application to nanoparticulate formulation. Int J Pharm Pharm Sci. 2016;8(12):149-55. doi: 10.22159/ijpps.2016v8i12.14473.

33. Padhye SG, Nagarsenker MS. Simvastatin solid lipid nanoparticles for oral delivery: formulation development and in vivo evaluation. Indian J Pharm Sci. 2013;75(5):591-8. PMID 24403661.

34. Westesen K, Bunjes $\mathrm{H}$, Koch MHJ. Physicochemical characterization of lipid nanoparticles and evaluation of their drug loading capacity and sustained release potential. J Control Release. 1997;48(2-3):223-36. doi: 10.1016/S01683659(97)00046-1.

35. Aungst BJ. Novel formulation strategies for improving oral bioavailability of drugs with poor membrane permeation or presystemic metabolism. J Pharm Sci. 1993;82(10):979-87. doi: 10.1002/jps.2600821008, PMID 8254497.

36. Maryam BZ, Akram P. Effect of surfactant concentration on the particle size, stability and potential zeta of beta carotene Nano lipid carrier. Int J Curr Microbiol Appl Sci. 2015;4(9):924-32.

37. Helgason T, Awad TS, Kristbergsson K, McClements DJ, Weiss J. Effect of surfactant surface coverage on formation of solid lipid 
nanoparticles (SLN). J Colloid Interface Sci. 2009;334(1):75-81. doi: 10.1016/j.jcis.2009.03.012, PMID 19380149.

38. Kovacevic A, Savic S, Vuleta G, Muller RH, Keck CM. Polyhydroxy surfactants for the formulation of lipid nanoparticles (SLN and NLC): effects on size, physical stability and particle matrix structure. Int J Pharm. 2011;406(1-2):16372. doi: 10.1016/j.ijpharm.2010.12.036, PMID 21219990.

39. Wolfgang M, Karsten M. Solid lipid nanoparticles production, characterization and applications. Adv Drug Deliv Rev. 2001;47(2):165-96

40. Silva AC, González-Mira E, García ML, Egea MA, Fonseca J, Silva R, Santos D, Souto EB, Ferreira D. Preparation, characterization and biocompatibility studies on risperidone-loaded solid lipid nanoparticles (SLN): high pressure homogenization versus ultrasound. Colloids Surf B Biointerfaces. 2011;86(1):158-65. doi: 10.1016/j.colsurfb.2011.03.035, PMID 21530187.

41. Amis TM, Renukuntla J, Bolla PK, Clark BA. Selection of cryoprotectant in lyophilization of progesterone-loaded stearic acid solid lipid nanoparticles. Pharmaceutics. 2020;12(9):1-15. doi: 10.3390/pharmaceutics12090892, PMID 32961738.

42. Hu FX, Neoh KG, Kang ET. Synthesis and in vitro anti-cancer evaluation of tamoxifen-loaded magnetite/PLLA composite nanoparticles. Biomaterials. 2006;27(33):5725-33. doi: 10.1016/j.biomaterials.2006.07.014, PMID 16890989. 